\title{
Using underweight for predicting stunting among children in India: Analysis from the Comprehensive National Nutrition Survey
}

\section{Sowmya Ramesh ( $\nabla$ sramesh@popcouncil.org )}

Population Council

\section{Rajib Acharya}

Population Council

\section{Avina Sarna}

Population Council

\section{Sana Ashraf}

Population Council

\section{Praween K. Agrawal}

IPE Global Limited, New Delhi

\author{
Akash Porwal \\ Population Council \\ Nizamuddin Khan \\ Population Council \\ Sila Deb \\ MoHFW, Government of India, New Delhi \\ Robert Johnston \\ United Nations Children's Fund India
}

\section{Research Article}

Keywords: undernutrition, stunting, underweight, children, CNNS, NFHS-4, India

Posted Date: April 13th, 2021

DOl: https://doi.org/10.21203/rs.3.rs-378194/v1

License: (1) (i) This work is licensed under a Creative Commons Attribution 4.0 International License.

Read Full License 


\section{Abstract}

Background: Stunting and underweight are the most commonly used indicators to assess the nutritional status of children. Prior research has highlighted the problems encountered while measuring the height of child. The current paper aims to assess the relationship between stunting and underweight and derive regression equations to predict stunting from underweight prevalence among children under five years of age.

Method: Data was drawn from 38,060 and 219,796 nationally representative sample of children aged 0-4 years, from Comprehensive National Nutrition Survey (CNNS, 2016-18) and National Family Health Survey 4 (NFHS-4, 2015-16), respectively. Anthropometric indicators, stunting and underweight was calculated based on the 2006 WHO Child Growth Standards. Univariate and bivariate analysis was done to obtain estimates for stunting and underweight. A series of regression models were run to obtain an estimate of percent stunted as a function of percent underweight at the national and regional level. Predicted stunting prevalence was estimated from regression equation for selected states and compared with observed prevalence from other studies. Data were analysed using STATA V.16.0.

Results: Nearly one out of four children under 5 years of age were stunted and underweight in CNNS and NFHS-4. Out of those stunted, $67 \%$ and $65 \%$ were underweight in CNNS and NFHS-4, respectively. At the national level, there was high correlation between the two indicators $(r>0.7)$ in both CNNS and NFHS-4, whereas at the regional level in NFHS-4, the correlation coefficient ranged from 0.32 for central region to 0.86 for southern region. At the national level the slope was 0.557 in CNNS and 0.610 in NFHS-4. At the regional level, it varied from 0.334 in the central region to 0.847 in the western region. Similarly, at the national level, the intercept (a) was almost same when we analyzed CNNS data or NFHS-4 data or both together ( 15), however, wide variability was observed between different regions (4.61 in western region to 30.14 in central region).

Conclusion: Our analysis shows that regression equations with child underweight prevalence may be used to predict stunting where the quality of length/ height measurement is poor or unavailable, in regions where high correlation between the two indicators was found.

\section{Introduction}

Malnutrition is a major public health problem in most developing countries, including India. It is well established that malnourished children are at a substantially greater risk for mortality and morbidity (15). Globally, among children under 5 years of age, nearly half of the deaths are attributed to undernutrition and most of these occur in low- and middle-income countries $(6,7)$. In India, the prevalence of stunting and underweight was reported to be $38 \%$ and $36 \%$, respectively, as per the recent National Family Health Survey - 4 (NFHS-4) in 2015-16 (8). Although, this is a decline from the prevalence reported in 2005-06 (NFHS-3), India still has the largest share of world's stunted children $(9,10)$. In India, malnutrition emerged as the leading risk factor for death among children under 5 years of age in every 
state of India in $2017.68 \cdot 2 \%$ of the total under-5 deaths could be attributed to malnutrition in 2017 (11). In addition, the deleterious effect of undernutrition on cognitive development among children has also been reported in many studies (12-14). Undernutrition during early years of life not only affects during childhood but also has a long-term impact during adulthood $(15,16)$. Recognizing the enormity of the problem, the Government of India (Gol) launched its flagship program, the POSHAN Abhiyaan, the Prime Minister's Overarching Scheme for Holistic Nutrition, in 2018, to reduce child and maternal malnutrition (17).

Stunting (height-for-age <-2 SD) and underweight (weight-for-age <-2 SD) are the most commonly used, WHO recommended indicators to assess the nutritional status and development of children (18). Nutrition interventions are designed based on the prevalence of these two indicators. Therefore, accurate estimation of stunting and underweight are critical to formulate appropriate public health policy to improve the nutritional status of children. However, several studies have highlighted the problems encountered while measuring the height of a child, such as, measuring length/ height of a child requires two observers, one to position the child properly and another to record the measurement. Very often two individuals may not be available and the reading taken by a single individual may not be accurate. Similarly, specific techniques are used for measuring height of children of different age groups (18). In infants less than 2 years of age, recumbent length is measured. If appropriate technique is not used, erroneous data will be obtained. Prior research has highlighted a difference in height of about $0.7 \mathrm{~cm}$ between measuring a child in recumbent and standing position (19). Additionally, length/height board, are often expensive and are not replaced even if they are damaged. Measuring height with a defective height board will lead to bias in the estimation of stunting. On the other hand, due to the availability of electronic scales at affordable prices the measurement of weight of children has become easier, faster and more accurate. Prior research has highlighted that use of digital scales increases accuracy and precision of the measurement (20).

Use of only weight-based indicators, might underestimate the level of malnutrition (21). On the other hand, if length or height of children are not assessed, food supplementation may lead to increasing prevalence of overweight or obese children. For example a stunted child with low weight-for-age but normal weight-for-length if given surplus food, may be at risk of becoming overweight or obese (22). Underweight measures whether the current weight of the child is appropriate for his or her age. Growth faltering can be detected with use of WAZ and regular monitoring sessions. If growth monitoring assessments are not done regularly i.e. monthly, measures of $\mathrm{WHZ}$ are recommended as sudden weight loss or growth faltering is detected at lower severities with WHZ and not with WAZ. Stunting measures cumulative inadequate health outcomes and is an ideal indicator of health inequity. However, acceptable growth monitoring data for stunting depends on use of correct tools, correct training of two individuals to measure height, regular monitoring and timely availability of data and data quality. 
Experts have indicated that, in the absence of high wasting levels, underweight and stunting can provide similar information i.e. both reflect long-term effect of nutrition among children (23). However, in India the prevalence of wasting among children under five years of age is high $(21 \%)$. In terms of severity index, prevalence of wasting above $15 \%$ is considered critical (24)

Current growth monitoring methods in India are shifting from use of underweight to stunting and wasting, implying measurement of height. Implementation of new protocols take time, may be several years to scale up across the country. Despite launch of POSHAN Abhiyaan in 2018, many states in the country, even by end of 2019 still do not have height scales to measure height for growth monitoring (25). When height boards are available, poor quality tools and measurement techniques can lead to unacceptable data quality. Until appropriate data quality for height is achieved, the question is whether underweight can be used to estimate stunting.

Therefore, the objective of the current analysis is (1) to assess the relationship between anthropometric indicators, stunting, and underweight, (2) to test the correlation between stunting and underweight and (3) to derive regression equations to predict stunting from prevalence of underweight among children under five years of age.

\section{Methods}

\section{Design, setting and sample}

Data for this analysis was drawn from two different surveys: the Comprehensive National Nutrition Survey (CNNS) and National Family Health Survey 4 (NFHS-4). The CNNS was conducted between 201618 to undertake comprehensive nutritional profiling of a nationally representative sample of children and adolescents; in this paper we use data from children 0-4 years of age. The CNNS adopted a multi-stage, stratified, probability proportion to size cluster sampling design to recruit children aged 0-4 years across 29 states and the capital Delhi (26). NFHS-4 is a nationally representative sample of women and children, recruited through a multi-stage cluster sample design, conducted during the period 2015-16, to provide information on the health and nutrition of women and children (8). From NFHS-4 data, for the current analysis we only focused on children under five years of age. In CNNS and NFHS-4, anthropometric measurements, height and weight was measured for children by trained and standardized health investigators. Overall, height and weight measurements were taken for 38,060 and 219,796 children aged 0-4 years in CNNS and NFHS-4, respectively. The overall survey design and sample size calculation for both CNNS and NFHS-4 has been described elsewhere $(8,26)$. 


\section{Ethical considerations}

The research was performed in accordance with the Declaration of Helsinki. Approval for conducting CNNS was obtained from the Ethics Committee of the Postgraduate Institute for Medical Education and Research in Chandigarh, India, and the Institutional Review Board of the Population Council in New York. Approval for the protocol for the NFHS-4 survey, was obtained from the International Institute for Population Sciences (IIPS) Institutional Review Board and the ICF Institutional Review Board. In both surveys, caregivers of children aged 0-4 years provided written informed consent for the study. As part of the consent process, the purpose of the study was described to the caregivers of children, their right to discontinue anytime during the study without any penalty and were assured of the confidentiality of data. They were also told that there will be no monetary benefits of participation in the study and the children will not experience any serious risks due to participation in the study.

\section{Measures}

The methodology for computing anthropometric indicators was based on the 2006 WHO Child Growth Standards (27). WHO Anthro-Plus software was used to calculate height-for-age and weight-for-age zscores. Children were considered to be stunted if their height-for-age was less than two standard deviation (<-2SD) below the WHO growth standards median; underweight, if their weight-for-age less than two standard deviation (<-2SD) below the WHO growth standards median and wasted if their weight for height was less than two standard deviation below the WHO growth standards median. Severe acute malnutrition (SAM) or severe wasting was defined if the child's weight for height/length z-score was $<-3 S D$; severe underweight if weight-for-age $z$-score $<-3 S D$ and severe stunting if height-for-age $z$-score $<-3 S D$.

Statistical analysis

Univariate and bivariate analysis was done to obtain national and state level estimates for stunting, underweight and wasting. The estimates were derived at national and state level from the two data sets (CNNS and NFHS-4). District level data set was used to derive estimates of stunting and underweight and that only from NFHS4. A database was created with state-level prevalence for stunting and underweight for CNNS and NFHS-4, and district level prevalence using only NFHS-4 data, as district-level estimates were not available for CNNS. Simple univariate regressions were run to obtain an estimate of percent stunted and percent severely stunted as a function of percent underweight and percent severely underweight at the national level, respectively, using CNNS and NFHS-4 data.. The country was divided into six regions and for each region, simple univariate regressions were run to estimate percent stunting as a function of percent underweight, using only NFHS-4 data.. The regression equations are presented with standard error (SE) of the slope, indicating variability of the estimate. P-value is presented reflecting 
the significance level of the null hypothesis $\beta$ (slope) $=0$. Correlation between underweight and stunting was also calculated. Further, predicted stunting prevalence was estimated from regression equation for selected states using NFHS-4 data and compared with observed prevalence of stunting from other nutritional surveys conducted in four states of India (Jharkhand, Odisha, Uttar Pradesh and Madhya Pradesh), during the period October 2016 to August 2017 among children below 5 years of age (28). Sampling weights were used to account for differential probabilities of selection of participants across states and differential non-response rates in both CNNS and NFHS-4. Data were analysed using STATA V.16.0.

\section{Results}

Overall, $23 \%$ of children under 5 years of age were stunted and underweight as per CNNS data (Table1) and among those who were stunted, $67 \%$ were also underweight (Table 3). Similar results were observed in NFHS-4, $25 \%$ of children under 5 years of age were both stunted and underweight (Table2) and among those who were stunted, $65 \%$ were also underweight (Table 3 ). In-terms of severe form of undernutrition, overall, nearly $7 \%$ of children were severely underweight and severely stunted in both CNNS and NFHS-4 ((Table 1 \& Table 2). Among those with severe stunting, two-fifth of them were also severely underweight in both the surveys (Table 3 ).

In all the regions and at the national level, we observed a significant relation between \% underweight and $\%$ stunted in both CNNS and NFHS-4. At the national level, a high correlation was observed $(r>0.7)$ between underweight and stunting. The prevalence was similar when using different dataset, with significantly high correlation. Similarly, the intercept (a) at the national level was almost same when we analyzed CNNS data or NFHS-4 data or both together ( 15). But between the different regions, the correlation coefficient ranged from as low as 0.32 for central region to 0.86 for southern region (Table 4, Figure 1). Similarly, wide variability was also observed in the intercept between different regions ranging from 4.61 for the western region to 30.14 for the central region. At the national level the slope was 0.557 (SE: 0.094) in CNNS and 0.610 (SE: 0.084) in NFHS-4. At the regional level, Wide variability was observed between different regions, ranging from 0.334 (SE: 0.084) in the central region to 0.847 (SE: 0.072) in the western region. Using the equations presented in table 4, for the national level, prevalence of stunting can be predicted using \% underweight. At the regional level, stunting can be predicted for regions with high correlation ( $r>0.7)$. For example, assuming that the prevalence of underweight in northern region is $27 \%$, the equation for stunting would be (Table 4$)$, \% stunting $=15.82+0.579 \times 27 \%=31.5 \%$. Using the Standard Error of 0.046 for slope, the $95 \%$ confidence interval would be: lower limit $=15.82+(0.579-$ $((1.96 \times 0.046) \times 27 \%))$; Upper limit $=15.82+(0.579+((1.96 \times 0.046) \times 27 \%))$. For central and northeastern region (low correlation between underweight and stunting), the results should be interpreted with caution. When we compared with other studies conducted in India is selected states, we observed that in three out of four state the observed prevalence of stunting reported in those studies were within the confidence interval estimated using the regression equations (Table 5)., A positive and significant relation was also observed between severe stunting and severely underweight (Table 4) in both CNNS and NFHS- 
4 data, at the national level. A high correlation was observed $(r>0.7)$ between stunting and underweight in both CNNS and NFHS-4.

\section{Discussion}

Stunting and underweight are the most frequently used and internationally recommended indicators of undernutrition among children. Studies indicate that these two indicators may be biologically related i.e. increase in weight may be associated with an increase in length or height because of better nutrition (14, $20,29,30)$. Since prior research pointed out several issues related to measuring children's length/ height (20), through our analysis we assessed the correlation between the stunting and underweight using two national large scale surveys and developed a simple predictive model for the prevalence of stunting using underweight. Through our analysis we found a positive and significant correlations between underweight and stunting at the national level in both CNNS and NFHS-4. Further, using the district level prevalence results from NFHS-4, positive and significant correlation was found at the regional level, although at the regional level the correlation ranged from as low as 0.32 for the central region to 0.86 for the southern region

We found that nearly two-third of those stunted were also underweight. This indicates that in locations where the data quality of height measurement is questionable or where it is difficult to capture height, underweight may be able to assess the nutrition status of children to a large extent. This corroborates with prior research in other countries where underweight was used as an indicator to assess the nutrition status of children and also predict stunting $(31,32)$. However, this method may have limitations in severe forms of undernutrition, a lower proportion of those severely stunted also were severely underweight $(<50 \%)$.

Regressing stunting on underweight resulted in similar slope at the national level, when using different survey data. However, the regression coefficients across regions were different. This indicates that the pattern of malnutrition and the relationship between the key nutritional indicators, underweight and stunting are unique to each region. In the southern region of the country, underweight explained $75 \%$ of the variability in stunting, whereas in the central region underweight only explained $10 \%$ of the variability in stunting. Prior research conducted in other countries as well as in India, highlights differences in the determinants of stunting and underweight $(23,33-37)$. The differences in the association between underweight and stunting, between different regions could be due to the differential influences of the determinants across regions i.e. different regional and local contextual factors such as, genetic differences, dietary habits, environmental factors, among others. To account for regional variations when deriving estimates the regional regression equation may be more appropriate. If state level contextual factors significantly and differentially influence the relationship between underweight and stunting, then it is important to consider state level regression equation and not the national or regional level equation. . 
We could not run state level regression models due to lack of sample size. Further research is needed to understand state level differences in the relationship between stunting and underweight.

Where the correlation is high, the equation can be used to assess if there is over estimation or under estimation of stunting prevalence in other surveys in the country, by examining the differences between observed and estimated \% stunted. An example has been presented in table 5 , using a survey that was conducted in four states of India during the period 2016-17 (28). The analysis indicates that in two out of four states, the survey reported lower prevalence of stunting compared to the regression model and in two states there was overestimation by the survey (Table 5). However, for the states belonging to the region (eastern India) where we found high correlation between underweight and stunting, the observed stunting prevalence was within the confidence interval of estimated stunting prevalence derived from the regression equation and in one of states from the central region, where we found low correlation between stunting and underweight, the observed stunting prevalence from the survey was outside the confidence interval of the estimated stunting prevalence (Table 5).

As indicated earlier in the paper, currently in India, growth monitoring method is changing from use of underweight to stunting and wasting. POSHAN Abhiyaan, which brought a lot of focus and momentum towards improving the nutritional status of children, was launched in 2018. As part of the program, growth monitoring devices including weighing scales and height measuring instruments - infantometers, and stadiometers were distributed. However, a recent report from NITI Aayog, a policy think tank of the Government of India, highlighted that many states in India in 2019 still do not have appropriate height measuring instruments (25). Anecdotal information from visits to Anganwadi Centres (AWC) in various states have highlighted data quality issues due to improper techniques used by the Anganwadi workers at the AWC, use of inappropriate equipment, and errors while entering the data. Till the time appropriate data quality for height is achieved, there is a need to use alternate growth monitoring indicator to estimate stunting. Prior research highlights the use of underweight, as in the absence of high wasting levels, underweight and stunting provide similar information about long-term health and nutritional experience (23). However, in India the prevalence of wasting is critically high in terms of severity index (8). Further, using only underweight may underestimate the magnitude of malnutrition in the country. Therefore, monitoring just weight-for-age may not be enough to address malnutrition, there is a need to also monitor length/ height-for-age. Therefore, our analysis presents a simple predictive model for estimating the prevalence of stunting using underweight.

While this study underlines the strong relationship between underweight and stunting, the results should be interpreted in light of certain limitations. First, in a country like India, there might be state level contextual factors that may influence the relationship between underweight and stunting. However, in the 
current analysis we could not undertake state level analysis due to small sample size. Second, predictive equations that are constructed depends on the quality of data used. In the current analysis we used CNNS and NFHS-4 data, both of which had rigorous quality control system put in place while collecting anthropometric data. However, issues related to the measurement of accurate and precise length/ height data may have led to some measurement errors that may have biased the correlation in some regions. Prior research in other countries indicated highest correlation coefficient for the 12-23 months age group, compared to other age groups among children. We did not undertake such analysis within each region due to limited sample size. Future research could provide critical insight regarding the relations between stunting and underweight for each age group. Further research may be required to derive state level regression equations, if state level contextual factor affect the relationship between stunting and underweight.

\section{Conclusion}

Findings from our analysis highlights positive and significant correlation between underweight and stunting. Further, the analysis indicates that the regression equations may be used to predict stunting prevalence in those regions which has sufficiently high correlation between the two indicators, (northern, southern, eastern and western region of the country) otherwise national level equation may be used along with their confidence limits where child stunting data is unavailable or the quality of length/ height measurement is poor.

\section{List Of Abbreviations}

AWC: Anganwadi Centres

CNNS: The Comprehensive National Nutrition Survey

Gol: Government of India

MoHFW: Ministry of Health and Family Welfare

NFHS: National Family Health Survey

NITI Aayog: The National Institution for Transforming India

POSHAN Abhiyaan: Prime Minister's Overarching Scheme for Holistic Nutrition

SAM: Severe acute malnutrition

WHO: The World Health Organization

WAZ: Weight-for-age z-scores

WHZ: Weight-for-age z-scores 


\section{Declarations}

\section{Ethics approval and consent to participate:}

Approval for conducting CNNS was obtained from the Ethics Committee of the Postgraduate Institute for Medical Education and Research in Chandigarh, India, and the Institutional Review Board of the Population Council in New York. Approval for the protocol for the NFHS-4 survey, was obtained from the International Institute for Population Sciences (IIPS) Institutional Review Board and the ICF Institutional Review Board. In both surveys, caregivers of children aged 0-4 years provided written informed consent for the study.

Consent for publication: Not applicable

\section{Availability of data and materials:}

Reasonable request for data used in this article may be made to the corresponding author.

The data used from NFHS-4 is available through The Demographic Health Survey Program's data distribution system.

Competing interests: None of the authors listed on this manuscript report any competing interest.

Funding: This work was supported by UNICEF under the CNNS knowledge products project and funded by Aditya and Megha Mittal.

Authors' contributions: SR and RA conceptualized the manuscript. PKA designed the survey, NK did data quality control and computed sampling weights. SR led the statistical analyses and SA, AP and NK contributed to analyses. SR and RA guided the analysis and interpreted the results. SR led the writing of the manuscript with inputs from RA, AS, RJ and SA. RA, AS, RJ, PKA, AP, NK and SD reviewed the manuscript.

Acknowledgements: Not applicable

\section{Ethics approval and consent to participate}

Ethics approval for conducting CNNS was obtained from the Ethics Committee of the Postgraduate Institute for Medical Education and Research in Chandigarh, India, and the Institutional Review Board of the Population Council in New York. Approval for the protocol for the NFHS-4 survey, was obtained from the International Institute for Population Sciences (IIPS) Institutional Review Board and the ICF Institutional Review Board. Caregivers of children aged 0-4 years provided written informed consent for the study and participation in the study was voluntary.

\section{References}


1. Chisti MJ, Tebruegge M, La Vincente S, Graham SM, Duke T. Pneumonia in severely malnourished children in developing countries - mortality risk, aetiology and validity of WHO clinical signs: a systematic review. Trop Med Int Health. 2009;14(10):1173-89.

2. Ginsburg AS, Izadnegahdar R, Berkley JA, Walson JL, Rollins N, Klugman KP. Undernutrition and pneumonia mortality. Lancet Glob Health. 2015;3(12):e735-6.

3. Monden CW, Smits J. Maternal height and child mortality in 42 developing countries. Am J Hum Biol. 2009;21(3):305-11.

4. Pelletier DL, Frongillo EA, Jr., Schroeder DG, Habicht JP. A methodology for estimating the contribution of malnutrition to child mortality in developing countries. J Nutr. 1994;124(10 Suppl):2106S-22S.

5. Pelletier DL, Frongillo EA, Jr., Schroeder DG, Habicht JP. The effects of malnutrition on child mortality in developing countries. Bull World Health Organ. 1995;73(4):443-8.

6. UNICEF. Levels and trends in child mortality: report 2014. . New York: United Nations Children's Fund; 2014.

7. World Health Organization. key facts, Malnutrition [Available from: https://www.who.int/newsroom/fact-sheets/detail/malnutrition.

8. International Institute for Population Sciences (IIPS) and ICF. National Family Health Survey (NFHS4), 2015-16: India. . Mumbai: IIPS.; 2017.

9. International Institute for Population Sciences (IIPS) and ICF. National Family Health Survey (NFHS3), 2005-06: India. . Mumbai: IIPS; 2007.

10. The Global Nutrition Report. https://globalnutritionreport.org/about/; 2018.

11. India State-Level Disease Burden Initiative Malnutrition C. The burden of child and maternal malnutrition and trends in its indicators in the states of India: the Global Burden of Disease Study 1990-2017. Lancet Child Adolesc Health. 2019;3(12):855-70.

12. Kavindra KK, Handa R, Prasad R. Effect of undernutrition on cognitive development of children. International Journal of Food, Nutrition and Public Health, . 2010;3(2).

13. Kar BR, Rao SL, Chandramouli BA. Cognitive development in children with chronic protein energy malnutrition. Behav Brain Funct. 2008;4:31.

14. McGregor IA, Rahman AK, Thompson B, Billewicz WZ, Thomson AM. The growth of young children in a Gambian village. Trans R Soc Trop Med Hyg. 1968;62(3):341-52.

15. Alderman $\mathrm{H}$, Hoddinott J, B. K. Long term consequences of early childhood malnutrition. Oxf Econ Pap 2006;58(3):450-74.

16. Victora CG, Adair L, Fall C, Hallal PC, Martorell R, Richter L, et al. Maternal and child undernutrition: consequences for adult health and human capital. Lancet. 2008;371(9609):340-57.

17. NITI Aayog Gol. PPOSHAN Anhiyaan 2018 [Available from: https://niti.gov.in/poshan-abhiyaan.

18. United Nations. How to weigh and measure children. Assessing the nutritional status of young children in household surveys. United Nations; 1986. 
19. Onis M. WHO Child Growth Standards based on length/height, weight and age. Acta Paediatr Suppl. 2006;95:76-85.

20. Blössner M, Onis MD, Uauy R. Estimating Stunting from Underweight Survey Data. Journal of human ecology. 2006.

21. Ruel MT, Rivera J, Habicht JP. Length screens better than weight in stunted populations. J Nutr. 1995;125(5):1222-8.

22. Uauy R, Kain J. The epidemiological transition: need to incorporate obesity prevention into nutrition programmes. Pub Health Nutr, . 2002;5:223-9.

23. Organization. WH. Global Database on Child Growth and Malnutrition: Descriptions. 2020 May 21: World Health Organization.

24. Victora CG. The association between wasting and stunting: an international perspective. Journal of Nutrition. 1992;122:1105-10.

25. NITI Aayog Gol. Transforming nutrition in India: Poshan Abhiyaan. A progress report September 2019. https://niti.gov.in/sites/default/files/2020-02/Poshan_Abhiyaan_2nd_Report_0.pdf. Niti Aayog; 2019.

26. Ministry of Health and Family Welfare (MoHFW) Gol, UNICEF and Population Council. Comprehensive National Nutrition Survey (CNNS) National Report. New Delhi.: Ministry of Health and Family Welfare (MoHFW), Government of India, UNICEF and Population Council.; 2019.

27. Group WHOMGRS. WHO Child Growth Standards based on length/height, weight and age. Acta Paediatr Suppl. 2006;450:76-85.

28. Sinha RK, Dua R, Bijalwan V, Rohatgi S, Kumar P. Determinants of Stunting, Wasting, and Underweight in Five High-Burden Pockets of Four Indian States. Indian J Community Med. 2018;43(4):279-83.

29. Kassie GW, Workie DL. Exploring the association of anthropometric indicators for under-five children in Ethiopia. BMC Public Health. 2019;19(1):764.

30. Wiersinga A, van Rens MM. The simultaneous effect of protein-calorie malnutrition on weight and height velocity. J Trop Pediatr Environ Child Health. 1973;19(2):141-51.

31. Nguefack-Tsague G, Kien. ATN, Fokunang. CN. Using weight-for-age for predicting wasted children in Cameroon. Pan Afr Med J 2013 14(96).

32. Victora CG, Gigante DP, Barros AJ, Monteiro CA, de Onis M. Estimating the prevalence of height for age deficits based on the prevalence of weight for age deficits among Brazilian children. Rev Saude Publica. 1998;32:321-7.

33. Chatterjee K, Sinha RK, Kundu AK, Shankar D, Gope R, Nair N ea. Social determinants of inequities in under-nutrition (weight-for-age) among under- 5 children: A cross sectional study in Gumla district of Jharkhand, India. Int J Equity Health. 2016;15(104).

34. Nestel P, Melara A, Rosado J, Mora JO. Undernutrition among Honduran children 12-71 months old. Rev Panam Salud Publica. 1999;6:256-65 
35. Singh S, Srivastava S, Upadhyay AK. Socio-economic inequality in malnutrition among children in India: an analysis of 640 districts from National Family Health Survey (2015-16). Int J Equity Health. 2019;18(1):203.

36. Sommerfelt EA, Stewart KM. Children's nutritional status. Demographic and Health Surveys Comparative Studies No. 12. Calverton, Maryland: Macro International Inc.; 1994.

37. Zere E, Mclntyre D. Inequities in under-five child malnutrition in South Africa. Int J Equity Health. 2003;2(1):7.

\section{Tables}

Table 1: Prevalence of stunting and underweight among children under 5 years of age, CNNS 2016-18 


\begin{tabular}{|llll|}
\hline State & \multicolumn{3}{l}{ Stunted and underweight } \\
\cline { 2 - 4 } & Total & $<-2 S D$ & $<-3 S D$ \\
\cline { 3 - 4 } & & $\%$ & $\%$ \\
\hline Jammu and Kashmir & 1068 & 5.9 & 1.8 \\
\hline Himachal Pradesh & 1136 & 13.4 & 2.2 \\
\hline Punjab & 977 & 14.2 & 3.1 \\
\hline Uttarakhand & 1076 & 13.4 & 1.6 \\
\hline Haryana & 1053 & 22.5 & 5.9 \\
\hline NCT of Delhi & 1611 & 18.9 & 3.0 \\
\hline Rajasthan & 1151 & 25.1 & 5.2 \\
\hline Uttar Pradesh & 1900 & 26.9 & 7.5 \\
\hline Bihar & 1350 & 28.4 & 7.9 \\
\hline Sikkim & 1025 & 6.6 & 0.9 \\
\hline Arunachal Pradesh & 1182 & 12.1 & 1.5 \\
\hline Nagaland & 1083 & 9.4 & 2.0 \\
\hline Manipur & 1143 & 21.6 & 6.3 \\
\hline Mizoram & 1128 & 9.6 & 1.5 \\
\hline Tripura & 1095 & 22.8 & 6.5 \\
\hline Meghalaya & 959 & 9.8 & 1.1 \\
\hline Assam & 1042 & 14.4 & 3.2 \\
\hline West Bengal & 991 & 22.9 & 4.4 \\
\hline Jharkhand & 1369 & 17.6 & 4.8 \\
\hline Odisha & 1164 & 19.0 & 3.6 \\
\hline Chhattisgarh & 28.7 & 7.7 \\
\hline Madhya Pradesh & 1099 & 18.1 & 3.3 \\
\hline Gujarat & 25.2 & 5.5 \\
\hline Maharashtra & 26.5 & 6.0 \\
\hline Andhra Pradesh & 1016 & 4.9 \\
\hline
\end{tabular}




\begin{tabular}{|llll|} 
Goa & 977 & 12.6 & 1.8 \\
\hline Kerala & 832 & 10.9 & 1.4 \\
\hline Telangana & 1740 & 10.6 & 2.4 \\
\hline India & 1003 & 19.4 & 3.8 \\
\hline
\end{tabular}

Table 2: Prevalence of stunting and underweight among children under 5 years of age, NFHS-4 2015-16 


\begin{tabular}{|c|c|c|c|}
\hline \multirow[t]{3}{*}{ State } & \multicolumn{3}{|c|}{ Stunted and underweight } \\
\hline & \multirow[t]{2}{*}{ Total } & $<-2 S D$ & $<-3 S D$ \\
\hline & & $\%$ & $\%$ \\
\hline Jammu and Kashmir & 7093 & 11.7 & 3.1 \\
\hline Himachal Pradesh & 2525 & 13.9 & 2.0 \\
\hline Punjab & 4746 & 13.2 & 2.9 \\
\hline Uttarakhand & 5007 & 17.8 & 4.3 \\
\hline Haryana & 6875 & 18.2 & 4.5 \\
\hline NCT of Delhi & 1145 & 20.7 & 3.6 \\
\hline Rajasthan & 14916 & 25.0 & 7.0 \\
\hline Uttar Pradesh & 36465 & 30.1 & 8.4 \\
\hline Bihar & 22275 & 33.8 & 10.6 \\
\hline Sikkim & 898 & 8.5 & 1.4 \\
\hline Arunachal Pradesh & 3851 & 12.0 & 3.1 \\
\hline Nagaland & 3825 & 11.9 & 2.1 \\
\hline Manipur & 5256 & 10.5 & 1.3 \\
\hline Mizoram & 4309 & 8.7 & 1.9 \\
\hline Tripura & 1188 & 14.1 & 2.3 \\
\hline Meghalaya & 3823 & 21.6 & 3.5 \\
\hline Assam & 8855 & 20.9 & 4.9 \\
\hline West Bengal & 4810 & 19.8 & 4.1 \\
\hline Jharkhand & 10507 & 33.6 & 10.0 \\
\hline Odisha & 9728 & 22.7 & 5.0 \\
\hline Chhattisgarh & 8230 & 24.1 & 6.0 \\
\hline Madhya Pradesh & 21272 & 29.6 & 8.5 \\
\hline Gujarat & 6444 & 26.2 & 7.1 \\
\hline Maharashtra & 7990 & 23.3 & 5.6 \\
\hline Andhra Pradesh & 2599 & 21.8 & 4.2 \\
\hline Karnataka & 6308 & 23.4 & 6.5 \\
\hline
\end{tabular}




\begin{tabular}{|llll|}
\hline Goa & 378 & 12.1 & 2.4 \\
\hline Tamil Nadu & 2235 & 8.9 & 1.6 \\
\hline Telangana & 6836 & 14.4 & 3.6 \\
\hline Andaman and Nicobar & 578 & 12.5 & 1.1 \\
\hline Chandigarh & 174 & 16.1 & 2.8 \\
\hline Dadra and Nagar Haveli & 277 & 26.0 & 6.9 \\
\hline Daman and Diu & 329 & 15.6 & 2.9 \\
\hline Lakshadweep & 281 & 14.8 & 3.0 \\
\hline Puducherry & 945 & 12.1 & 4.1 \\
\hline India & 225002 & $\mathbf{2 5 . 0}$ & 6.7 \\
\hline
\end{tabular}

Table 3: Prevalence of underweight among children stunted, CNNS (2016-18) and NFHS-4 (2015-16) 


\begin{tabular}{|c|c|c|c|c|}
\hline \multirow[t]{3}{*}{ State } & \multicolumn{4}{|c|}{ Underweight among Stunted } \\
\hline & \multicolumn{2}{|l|}{$<-2 S D$} & \multicolumn{2}{|l|}{$<-3 S D$} \\
\hline & CNNS (\%) & NFHS (\%) & CNNS (\%) & NFHS (\%) \\
\hline Jammu and Kashmir & 38.2 & 42.3 & 31.4 & 25.9 \\
\hline Himachal Pradesh & 47.2 & 52.7 & 32.2 & 26.3 \\
\hline Punjab & 58.3 & 51.1 & 38.3 & 35.0 \\
\hline Uttarakhand & 44.8 & 52.7 & 16.6 & 30.1 \\
\hline Haryana & 64.6 & 53.4 & 50.3 & 30.2 \\
\hline NCT of Delhi & 65.5 & 64.4 & 30.8 & 33.7 \\
\hline Rajasthan & 68.3 & 63.9 & 39.5 & 40.4 \\
\hline Uttar Pradesh & 69.2 & 65.0 & 48.3 & 39.6 \\
\hline Bihar & 67.7 & 69.9 & 43.6 & 45.8 \\
\hline Sikkim & 30.2 & 28.7 & 13.2 & 11.3 \\
\hline Arunachal Pradesh & 43.2 & 41.0 & 14.0 & 25.9 \\
\hline Nagaland & 36.0 & 41.9 & 18.4 & 20.8 \\
\hline Manipur & 33.4 & 36.3 & 14.1 & 15.1 \\
\hline Mizoram & 35.8 & 31.3 & 15.6 & 21.4 \\
\hline Tripura & 45.1 & 58.7 & 23.8 & 28.2 \\
\hline Meghalaya & 56.7 & 49.2 & 25.6 & 18.2 \\
\hline Assam & 54.4 & 57.6 & 31.5 & 34.3 \\
\hline West Bengal & 74.9 & 60.6 & 49.0 & 39.7 \\
\hline Jharkhand & 79.2 & 73.8 & 54.5 & 49.2 \\
\hline Odisha & 62.3 & 66.6 & 40.5 & 40.4 \\
\hline Chhattisgarh & 71.3 & 64.1 & 48.1 & 38.5 \\
\hline Madhya Pradesh & 67.1 & 70.5 & 42.3 & 46.0 \\
\hline Gujarat & 65.1 & 68.4 & 41.0 & 43.0 \\
\hline Maharashtra & 59.1 & 68.0 & 34.3 & 44.4 \\
\hline Andhra Pradesh & 68.7 & 69.2 & 43.4 & 39.1 \\
\hline Karnataka & 70.2 & 64.4 & 52.0 & 38.8 \\
\hline
\end{tabular}




\begin{tabular}{|lllll|}
\hline Goa & 64.2 & 60.4 & 34.4 & 27.6 \\
\hline Tamil Nadu & 53.3 & 44.5 & 26.9 & 23.3 \\
\hline Telangana & 53.7 & 52.8 & 41.7 & 33.6 \\
\hline India & 66.1 & 69.5 & 43.0 & 47.6 \\
\hline
\end{tabular}

Table 4: Correlation and regression analysis results of the prevalence of stunting on underweight among children under 5 years of age 


\begin{tabular}{|c|c|c|c|c|c|c|c|}
\hline Region & $\begin{array}{l}\text { \# of } \\
\text { data } \\
\text { points }\end{array}$ & $\begin{array}{l}\% \\
\text { stunting= } \\
a+\beta \times X\end{array}$ & $\begin{array}{l}\text { SE } \\
(\beta)\end{array}$ & $95 \% \mathrm{Cl}$ for $\beta$ & p-value & r2 & Correlation \\
\hline \multicolumn{8}{|l|}{$\begin{array}{l}\text { Stunting and } \\
\text { underweight }\end{array}$} \\
\hline $\begin{array}{l}\text { National (only } \\
\text { CNNS data) }\end{array}$ & 30 & $\begin{array}{l}15.53+ \\
0.557 * x\end{array}$ & 0.094 & $\begin{array}{l}0.3657693 \\
0.749053\end{array}$ & $<0.0001$ & 0.559 & 0.7477 \\
\hline $\begin{array}{l}\text { National (only } \\
\text { NFHS-4 data) }\end{array}$ & 30 & $\begin{array}{l}15.65+ \\
0.610 * X\end{array}$ & 0.084 & $\begin{array}{l}0.4373314 \\
0.7834189\end{array}$ & $<0.0001$ & 0.6509 & 0.8068 \\
\hline $\begin{array}{l}\text { National } \\
\text { (CNNS \& } \\
\text { NFHS-4 data) }\end{array}$ & 60 & $\begin{array}{l}15.34+ \\
0.594 * X\end{array}$ & 0.062 & $\begin{array}{l}0.4689596 \\
0.719125\end{array}$ & $<0.0001$ & 0.6091 & 0.7804 \\
\hline $\begin{array}{l}\text { North (NFHS- } \\
\text { 4) }\end{array}$ & 131 & $\begin{array}{l}15.82+ \\
0.579 * x\end{array}$ & 0.046 & $\begin{array}{l}0.4878058 \\
0.6701202\end{array}$ & $<0.0001$ & 0.5504 & 0.7419 \\
\hline $\begin{array}{l}\text { South (NFHS- } \\
4)\end{array}$ & 109 & $\begin{array}{l}6.51+0 \\
.825 * X\end{array}$ & 0.046 & $\begin{array}{l}0.7341588 \\
0.9155731\end{array}$ & $<0.0001$ & 0.7523 & 0.8674 \\
\hline East (NFHS-4) & 111 & $\begin{array}{l}9.27+ \\
0.785^{\star} x\end{array}$ & 0.048 & $\begin{array}{l}0.6909209 \\
0.8795052\end{array}$ & $<0.0001$ & 0.7142 & 0.8451 \\
\hline West (NFHS-4) & 64 & $\begin{array}{l}4.61+ \\
0.847 * x\end{array}$ & 0.072 & $\begin{array}{l}0.7022485 \\
0.9910205\end{array}$ & $<0.0001$ & 0.6891 & 0.8301 \\
\hline $\begin{array}{l}\text { Central (NFHS- } \\
4)\end{array}$ & 139 & $\begin{array}{l}30.14+ \\
0.334 * X\end{array}$ & 0.084 & $\begin{array}{l}0.1680064 \\
0.4990188\end{array}$ & $<0.0001$ & 0.1039 & 0.3223 \\
\hline $\begin{array}{l}\text { North-east } \\
\text { (NFHS-4) }\end{array}$ & 86 & $\begin{array}{l}19.99+ \\
0.571 * X\end{array}$ & 0.082 & $\begin{array}{l}0.4085666 \\
0.7336998\end{array}$ & $<0.0001$ & 0.3675 & 0.6062 \\
\hline \multicolumn{8}{|c|}{ Severe stunting and Severe underweight } \\
\hline $\begin{array}{l}\text { National (only } \\
\text { CNNS data) }\end{array}$ & 30 & $\begin{array}{l}5.15+ \\
0.764^{*} x\end{array}$ & 0.136 & $\begin{array}{l}0.4863227 \\
1.04212\end{array}$ & $<0.0001$ & 0.5312 & 0.7289 \\
\hline $\begin{array}{l}\text { National (only } \\
\text { NFHS-4 data) }\end{array}$ & 36 & $\begin{array}{l}4.34+ \\
1.050^{\star} x\end{array}$ & 0.119 & $\begin{array}{l}0.8084089 \\
1.292151\end{array}$ & $<0.0001$ & 0.6961 & 0.8343 \\
\hline $\begin{array}{l}\text { National } \\
\text { (CNNS \& } \\
\text { NFHS-4 data) }\end{array}$ & 66 & $\begin{array}{l}4.62+ \\
0.935^{\star} x\end{array}$ & 0.093 & $\begin{array}{l}0.7497084 \\
1.120473\end{array}$ & $<0.0001$ & 0.6134 & 0.7832 \\
\hline
\end{tabular}

$a=$ intercept, $\beta=$ slope and $x=\%$ underweight (Regression equation: $\%$ stunting = intercept + slope $\times \%$ underweight)

North: Delhi, Haryana, Himachal Pradesh, Jammu \& Kashmir, Punjab, Rajasthan, Uttarakhand

South (districts from the states): Tamil Nadu, Karnataka, Andhra Pradesh, Kerala, Telangana

East (district from the states): Bihar, Jharkhand, Odisha, West Bengal 
West (district from the states): Gujarat, Goa, Maharashtra

Central (district from the states): Chhattisgarh, Madhya Pradesh, Uttar Pradesh

Northeast (districts from the states): Arunachal Pradesh, Assam, Tripura, Manipur, Meghalaya, Nagaland, Mizoram, Sikkim

Table 5: Comparison between observed prevalence of stunting (other survey) and estimated prevalence of stunting using the regional specific regression equation, among children under 5 years of age

\begin{tabular}{|c|c|c|c|c|c|}
\hline Region & $\begin{array}{l}\text { Year } \\
\text { of } \\
\text { survey }\end{array}$ & $\begin{array}{l}\% \\
\text { underweight } \\
\text { (NFHS-4) }\end{array}$ & $\begin{array}{l}\% \text { stunting } \\
\text { observed (other } \\
\text { surveys) }\end{array}$ & $\begin{array}{l}\text { \% stunting estimated } \\
\text { (from regression } \\
\text { equation) }\end{array}$ & $\Delta$ \\
\hline $\begin{array}{l}\text { Koraput (Odisha) } \\
\text { (NFHS-4) }\end{array}$ & 2017 & 55.8 & 50.1 & $53.1(47.8-58.3)$ & -2.97 \\
\hline $\begin{array}{l}\text { Khuntpani } \\
\text { (Jharkhand) } \\
\text { (NFHS-4) }\end{array}$ & 2016 & 72.5 & 70.7 & $66.2(59.4-73.0)$ & 4.52 \\
\hline $\begin{array}{l}\text { Naraini (Uttar } \\
\text { Pradesh) (NFHS- } \\
\text { 4) }\end{array}$ & 2017 & 59.7 & 58.9 & $50.1(40.2-59.9)$ & 8.82 \\
\hline $\begin{array}{l}\text { Kesla (Madhya } \\
\text { Pradesh) (NFHS- } \\
\text { 4) }\end{array}$ & 2017 & 46.5 & 37.9 & $45.7(38.0-53.3)$ & -7.77 \\
\hline
\end{tabular}

$\Delta=\%$ stunting estimated $-\%$ stunting observed

Figure 1: Correlation between underweight and stunting by region, NFHS -4, 2015-16

\section{Figures}



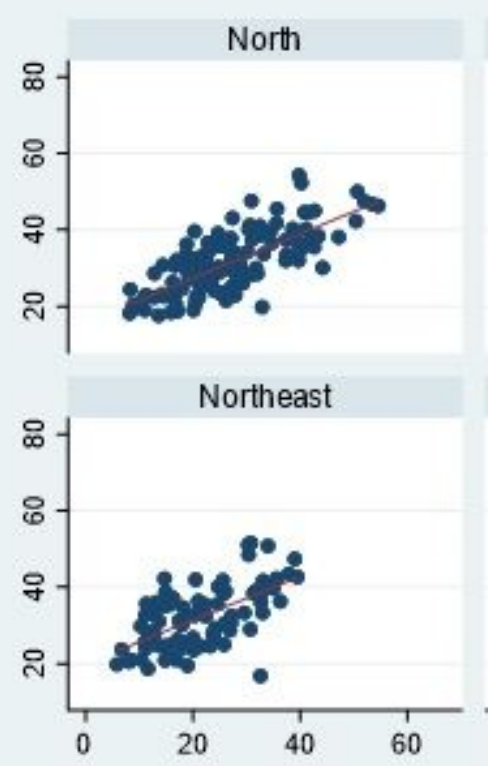

- \% stunted
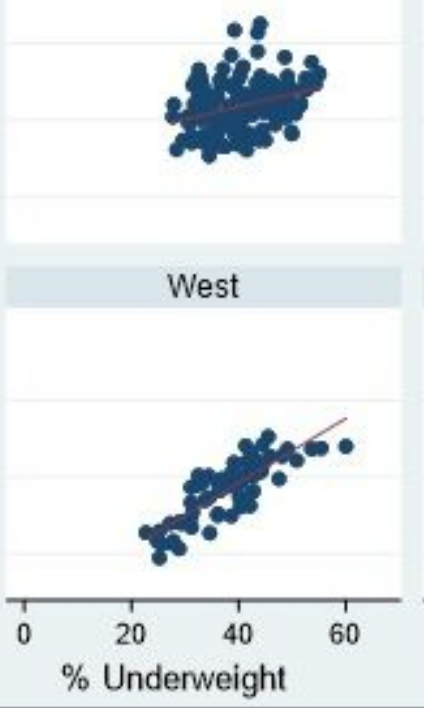

Fitted values

Graphs by Region

\section{Figure 1}

Correlation between underweight and stunting by region, NFHS -4, 2015-16 